\title{
The Effect of Procrastination on Academic Performance of Online Students at a Hispanic Serving Institution
}

\author{
Irma S. Jones \\ University of Texas Rio Grande Valley \\ Dianna C. Blankenship
University of Texas Rio Grande Valley
}

Procrastination is a universal conundrum among undergraduates. Furthermore, the effects such procrastination may have on academic performance is a concern. This study seeks to better understand the relationship between academic performance and the actual time of submission of assignments relative to the deadline imposed on those submissions. The authors investigated the effect of academic assignment submission time and the academic grades earned before, on, and after the assignment submission deadline. These results suggest that the earlier assignments are submitted, the higher the grades tend to be. Therefore, if faculty can help undergraduate students cultivate the habit of earlier submission of assignments, the better those students should do in their studies.

\section{INTRODUCTION}

Over the last couple of decades, undergraduate student behavior has produced many studies in educational and psychological research. Some of those studies had to do with undergraduate student characteristics of procrastination in submitting academic assignments. Because $80-95 \%$ of college students procrastinate ${ }^{1}$ this behavior has received significant attention in educational inquiry. Procrastination can be defined as the intentional delay of an intended action despite an awareness of negative outcomes ${ }^{2}$. It is a voluntary but irrational delay of an intended course of action, with nonbeneficial consequences ${ }^{3}$. The action may transcend many settings, including non-academic settings, and clearly decreases the attainment of assignments or goals ${ }^{4}$. $n$ education and training, the term academic procrastination is commonly used to denote the delay in academic activities. This delay may be intentional, incidental and/or habitual but significantly affects learning and achievement of university students ${ }^{5}$. Procrastination can appear as a tendency, an attitude and/or behavioral trait which Shah (2000) described as, "an indecisive state lacking in will power and vitality to do work." To better understand the relationship between the actual time of submission of online assignments and the deadline imposed on those submissions, this study will seek to understand the extent of the link between the timing of student submission of online assignments and the academic performance or quality of that submission. 


\section{PROCRASTINATION AND ITS EFFECT ON ACADEMIC PERFORMANCE}

More than twenty-five years ago, Leidner and Jarvenpaa (1993) identified technology, instructor, and student characteristics as three main variables that affected student success in online education. For this research study, the authors examined the student characteristic of procrastination and its effect on online academic performance.

Arnott and Dacko (2014) from the University of Warwick Business School tracked the submission of online end-of-term assignments for 777 first- and third-year undergraduate marketing students over a five-year period. Their research stemmed from concern that grades reflected not only student knowledge but also students' tendency to put things off. Submission times were collated into 18-time categories from "up to the last 24 hours" down to "the last minute." They found students who submitted their work at least a day before the deadline received a mean grade of about 64 while whose who waited until the last minute earned a mean grade of 59. They also discovered that $86.1 \%$ of the students waited until the last 24 hours to turn in work, earning an average score of 64.04 , compared to early submitters' average of 64.32. Interestingly, the average score for the most part continued to drop by the hour; those who waited until the last minute to turn in the assignment had the lowest average grade of 59. The researchers concluded that students who turned in assignments at the last-minute face a 5\% drop in marks when compared with those students who submit their assignments 24 hours or more before it was due.

Informal analytic results covering a typical week of online course participation patterns in an anonymous university showed timely submission of most assignments. However, the median submission time of assignments before due date was only 30 minutes while the median past due submission time of assignments was 1.2 hours $^{6}$.

Rotenstein, Davis and Tatum (2009) researched time of submission of seven online assignments for 297 graduate students taking a financial accounting course for non-accounting majors. Utilizing a program that tracked time of assignment download as well as submission, they reviewed two measures of procrastination from a pool of 2051 assignments. They studied Start (the number of hours from submission download to due date) and Finish (the number of hours from submission to due date). Their conclusion was that "early birds" (students who started or finished sooner) received significantly higher grades than "just-in-timers" (students who started or finished later).

Distance education courses place more demand on self-regulation than traditional face-to-face education ${ }^{7}$. Accordingly, it is no surprise that time management and independent learning skills are critical to success in online education ${ }^{8}$. Students who have disabling and habitual procrastinating behavior patterns lack these skills. Parker humorously (2015) describes them as "human ostriches" because they automatically stick their heads in the sand to avoid dealing with unpleasant, complicated, frustrating or boring tasks.

Kim and Seo (2015) synthesized findings from a meta-analysis of 33 relevant studies involving a total of 38,529 participants. Their analysis revealed procrastination to be negatively correlated with academic performance. However, this relationship was not significant and was influenced by the choice of measures or indicators as well as the use of self-report scales and demographic characteristics of the participants. They also reported academic procrastination to be most strongly correlated with academic performance in younger students.

Although the author's study did not use self-reported data but used actual time of submission as documented by the Blackboard Learning Management System and did not inquire into other measures or demographic characteristics, the results are similar in that it was also observed the greater the procrastination to be negatively correlated with academic performance. In this study, $56 \%$ of those submitting assignments late earned a grade of an "F."

Michinov, Brunot, Le Bohec, Juhel, \& Delaval (2011) found that online students who procrastinated earned lower grades than non-procrastinators. However, this relationship was mediated by the level of the learners' participation in discussion forums. Because high procrastinators were less likely to participate in online discussion forums, they suggested instructors utilize strategies to increase participation in the online learning environment. 
Although all students in this study were undergraduates, there was no differentiation between student classifications. However, Levy and Ramim (2012) found more sophomores $(71.6 \%)$ turned in assignments on the due date compared to juniors (57.3\%) and seniors $(61.6 \%)$.

Mlynarska, Greene, \& Cunningham. (2016) looked at Moodle data covering 360 courses, 2194 assignments, and 71,077 assignment submissions from the University College, Dublin. They then analyzed a subset of 60 complete assignments submitted on or before the deadline and correlated grades with the amount of time remaining between submission and the deadline. With one anomaly, they found most of the assignments ( 42 out of 60 ) positively correlated between grade and time of submission. They also noted that first year undergraduate students were most likely to have negative correlations between grade and time of submission. Their interpretation was that first-year students have not developed good time management practices. This is in line with the report of Kim and Seo (2015) that academic procrastination is more strongly correlated with academic performance in younger students. Considering these findings, Arnott and Dacko's (2014) suggestion that procrastination be addressed in first year students might help alleviate this tendency.

Grunschel, Patrzek, Klingsieck \& Fries (2018) found that procrastinators who completed a five-week group training based on a cyclical process model of self-regulated learning significantly reduced academic procrastination and reported improved time management skills.

Utilizing data analytic techniques, Levy and Ramim (2012) reviewed a dataset of 1629 online exam records over a period of five terms. They found than $58 \%$ of students turned in assignments on the last day of a weeklong task completion window. Furthermore, the procrastinators earned significantly lower scores (82.9) than the non-procrastinators (87.7). The following section describes the methodology used in this study.

\section{METHODOLOGY}

The data set for this study comprises one semester (Spring 2018) worth of assignments submitted by undergraduate online Criminal Justice and Technology Education and Corporate Training students at a southern Hispanic Serving University. Using this data, there were 704 different assignments and related information such as date of submission, time of actual submission and grades earned by students on the submitted assignments.

\section{FINDINGS}

Using the spring 2018 data set with 704 assignments, the authors divided this data set into three different time intervals: 1) assignments submitted by students before the actual submission deadline, 2) assignments submitted by student's On the actual assignment deadline and then 3 ) assignments submitted by students after the deadline date.

Table 1 below indicates the number of assignments submitted using the Before, On and After assignment deadline categories.

TABLE 1

COMPLETE DATA SET IN THREE INTERVALS - N=704

\begin{tabular}{|l|r|r|}
\hline \multicolumn{1}{|c|}{ Intervals } & Submissions & Percentages of Submissions \\
\hline Before Deadline & 246 & $49 \%$ \\
\hline On Deadline & 385 & $55 \%$ \\
\hline After Deadline & 73 & $10 \%$ \\
\hline
\end{tabular}

Using the three categories labeled: Before, On, and After, the authors then compared each specific timeline with the grades earned on the assignments. Tables 1A, 1B and 1D illustrate each individual grade category. 
Table 1A represents all the assignments that were submitted early or before the submission deadline established. Fifty-seven percent of the submissions received A's on the assignment and $28 \%$ received B's. These figures indicate that overall, students that submitted their work early tended to receive higher grades. Only $6 \%$ of the assignments received grades on the lower end of the spectrum with D's and F's.

TABLE 1A

THE FIRST INTERVAL BEFORE THE SUBMISSION DEADLINE - N=246

\begin{tabular}{|l|r|r|}
\hline Grades Earned & Assignments & Overall Percentage \\
\hline $90-100$ & 140 & $57 \%$ \\
\hline $80-89$ & 68 & $28 \%$ \\
\hline $70-79$ & 22 & $9 \%$ \\
\hline $60-69$ & 10 & $4 \%$ \\
\hline Below 50 & 6 & $2 \%$ \\
\hline
\end{tabular}

Table 1B represents all the assignments that were submitted on the established deadline date. Eightyseven percent of the submissions earned a grade of A, B or C with $77 \%$ in the top two grade levels.

TABLE 1B

THE SECOND INTERVAL ON THE SUBMISSION DEADLINE - N=385

\begin{tabular}{|l|r|r|}
\hline Grades Earned & Assignments & Overall Percentage \\
\hline $90-100$ & 182 & $47 \%$ \\
\hline $80-89$ & 116 & $30 \%$ \\
\hline $70-79$ & 40 & $10 \%$ \\
\hline $60-69$ & 28 & $7 \%$ \\
\hline Below 50 & 19 & $5 \%$ \\
\hline
\end{tabular}

The authors then totaled the grades for all assignments that were submitted before and on the deadline dates as depicted in Table 1C. These submissions yielded 51\% A's, 29\% B's, 10\% C's, 6\% D's and $4 \% \mathrm{~F}$ 's. These totals represent $96 \%$ passing grades and only $4 \%$ failing grades.

TABLE 1C

THE COMBINATION FIRST AND SECOND INTERVAL BEFORE AND ON THE SUBMISSION DEADLINE $-\mathbf{N}=631$

\begin{tabular}{|l|r|r|}
\hline \multicolumn{1}{|c|}{ Grades Earned } & Assignments & Overall Percentage \\
\hline $90-100$ & 322 & $51 \%$ \\
\hline $80-89$ & 184 & $29 \%$ \\
\hline $70-79$ & 62 & $10 \%$ \\
\hline $60-69$ & 38 & $6 \%$ \\
\hline Below 50 & 25 & $4 \%$ \\
\hline
\end{tabular}

Table1D represents all the assignments that were submitted after the deadline dates. Of the 73 assignments that were submitted after the deadline, 6 or $8 \%$ earned A's, 5 or $7 \%$ earned B's, 8 or $11 \%$ earned C's, 13 or $18 \%$ earned D's and 43 or $56 \%$ earned F's. Forty-one or $56 \%$ of the assignments earned failing grades which is more than the first two data sets in Tables $1 \mathrm{~A}$ and $1 \mathrm{~B}$ combined. 


\section{TABLE 1D}

\section{THE THIRD INTERVAL AFTER THE SUBMISSION DEADLINE - N=73}

\begin{tabular}{|l|r|r|}
\hline Grades Earned & Assignments & Overall Percentage \\
\hline $90-100$ & 6 & $8 \%$ \\
\hline $80-89$ & 5 & $7 \%$ \\
\hline $70-79$ & 8 & $11 \%$ \\
\hline $60-69$ & 13 & $18 \%$ \\
\hline Below 50 & 41 & $56 \%$ \\
\hline
\end{tabular}

Of the complete data set with which this study began containing 704 assignment submissions, $9 \%$ of all the assignments earned failing grades with the majority submitted after the assignment deadline.

TABLE 2

$$
\text { COMBINATION OF COMPLETE DATA SET }-\mathbf{N}=704
$$

\begin{tabular}{|c|r|r|}
\hline Grades Earned & Assignments & Overall Percentage \\
\hline A & 328 & $47 \%$ \\
\hline B & 189 & $27 \%$ \\
\hline C & 70 & $10 \%$ \\
\hline D & 51 & $7 \%$ \\
\hline F & 66 & $9 \%$ \\
\hline
\end{tabular}

\section{CONCLUSIONS \& RECOMMENDATIONS}

The findings in this study show that when students submitted assignments early or on the established assignment deadlines, they tend to do better than when they submitted assignments late or after the deadline.

The findings also indicated that students that missed the due date deadline and submitted assignments later than the due date, the number of submissions at that point received $50 \%$ or more failing grades.

While Goroshit (2018) noted the need for further study of academic interventions for academic procrastination, instructors can act to help their online students. For example, they can recommend procrastination surveys, offer helpful suggestions, explain how timely submission of online assignments is linked to academic performance, and provide links to additional resources to help students recognize procrastination tendencies, and adopt strategies to deal with procrastination.

One recommendation for future studies might be to include in the course syllabus provided to the students at the beginning of a class that no late work will be accepted in class assignment submissions. It would be one way to understand if absolutely prohibiting late work has any influence on submission grades.

Another recommendation for future studies might be to provide measures/interventions that control or minimize procrastination characteristics including guidance and counseling services for study habits and completion of assignments, positive encouragement and reward for good academic performance, and developing and maintaining academic relationships with peers and students for peer discussions.

\section{ENDNOTES}

1. Steel, 2007.

2. Steel, 2007.

3. Steel, 2007.

4. Hussian \& Sultan, 2010. 
5. Hussain \& Sultan, 2010.

6. Biray, 2016.

7. Klingsieck, Fries, Horz, \& Hofer, 2012.

8. Liu, Gomez, Khan, \& Yen, 2007.

\section{REFERENCES}

Arnott, D., \& Dacko, S. (2014, June 4). Time of submission: An indicator of procrastination and a correlate of performance on undergraduate marketing assignments. Paper presented at the $43^{\text {rd }}$ European Marketing Academy Conference: Paradigm Shifts \& Interactions. Valencia, Spain. Retrieved from http://emac2014.emaconline.org/adeit.estaticos.econgres.es/2014EMAC/guia2014.pdf

Biray. (2016, January 18). Data reveals interesting relationship between assignment submission time and assignment due time. [Blog post]. Retrieved from https://community.canvaslms.com/groups/bigdata/blog/2016/01/18/data-reveals-interesting-relationship-between-assignment-submission-timeand-assignment-due-time.

Goroshit, M. (2018, February 27). Academic procrastination and academic performance: An initial basis for intervention. Journal of Prevention \& Intervention in the Community, 46(2), 131-142.

Grunschel, C., Patrzek, J., Klingsieck, K. B., \& Fries, S. (2018). I'll stop procrastinating now! Fostering specific processes of self-regulated learning to reduce academic procrastination. Journal of Prevention \& Intervention in the Community, 46(2), 143-157.

DOI: 10.1080/10852352.2016.1198166

Hussain, I., \& Sultan, S. (2010, February 21). Analysis of procrastination among university students. Elsevier Ltd. DOI: 10.1016/j.sbspro.2010.07.385.

Kim, K. R., \& Seo, E. H. (2015). The relationship between procrastination and academic performance: A meta-analysis. Personality and Individual Differences, 82, 26-33. Doi: 10.1016/j.paid.2015.02.038

Klingsieck, K. B., Fries, S., Horz, C., \& Hofer, M. (2012). Procrastination in a distance university setting. Distance Education, 33(3), 295-310. DOI: 10.1080/01587919.2012.723165

Leidner, D. E., \& Jarvenpaa, S.L. (1993). The information age confronts education: Case studies on electronic classroom. Information Systems Research, 4(1), 24-54.

Levy, Y., \& Ramim, M. M. (2012). A study of online exams procrastination using data analytics techniques. Interdisciplinary Journal of E-Learning and Learning Objects (8). Retrieved from http://www.ijello.org/Volume8/IJELLOv8p097-113Levy0804.pdf

Liu, S., Gomez, J., Khan, B., \& Yen, C. (2007). Toward a learner-oriented community college online course dropout framework. International Journal on E-Learning, 6(4), 519-542. Waynesville, $\mathrm{NC}$ : Association for the Advancement of Computing in education. Retrieved from https://www.learntechlib.org/primary/p/21789/

Michinov, N., Brunot, S., Le Bohec, O., Juhel J., \& Delaval, M. (2011). Procrastination, participation, and performance in online learning environments. Computers \& Education 56(1), 243 252. https://doi.org/10.1016/j.compedu.2010.07.025.

Mlynarska, E., Greene, D., \& Cunningham, P. (2016). Indicators of good student performance in Moodle activity data. Downloaded from https://arxiv.org/abs/1601.02975

Parker, D. (2015). The more you do the better you feel. Brooklyn, NY: Darwin Bay Publishing.

Rotenstein, A., Davis H. Z., \& Tatum, L. (2009). Early birds versus just-in-timers: The effect of procrastination on academic performance of accounting students. Journal of Accounting Education, 27(4), 223-232. Elsevier, Ltd. doi:10.1016/j.jaccedu.2010.08.001.

Steel, P. (2007). The nature of procrastination: A meta-analytic and theoretical review of quintessential self-regulatory failure. Psychological Bulletin, 133(1), 65-94.

Shah, A. S. (2000). Exploring the world of English: A practical course in composition. Lahore: Markazi Kutub Khana, Elsevier Ltd. 